\title{
Luminescent Ir(III) complexes containing benzothiazole-based tridentate ligands: synthesis, characterization, and application to organic light-emitting diodes
}

\author{
Junpei Kuwabara, ${ }^{a}$ Tomomi Namekawa, ${ }^{a}$ Masa-aki Haga, ${ }^{b}$ Takaki Kanbara ${ }^{* a}$ \\ ${ }_{5}$ Received (in $\left.X X X, X X X\right)$ Xth $X X X X X X X X X 20 X X$, Accepted Xth $X X X X X X X X X 20 X X$ \\ DOI: $10.1039 / b 000000 x$
}

Ir(III) complexes that contain benzothiazole-based tridentate ligands were synthesized and their crystal structures and luminescent properties were examined. A 10 neutral complex had a high quantum yield (89\%) and performed well as an emissive material for organic lightemitting diodes.

Keywords: Ir complex / Pincer ligand / phosphorescence / ${ }_{15}$ OLEDs

Iridium complexes composed of cyclometallated ligands are promising phosphorescent materials for organic light-emitting diodes (OLEDs). ${ }^{1}$ Anionic bidentate ligands such as 220 phenylpyridine (ppy) and 2-phenylbenzothiazole (bt) are often found in the structures of emissive Ir complexes as cyclometallated ligands. $^{2}$ In particular, $\operatorname{Ir}(\mathrm{ppy})_{3}$ is used widely in OLEDs owing to its high quantum yield and thermal stability. In general, tridentate cyclometalated ligands, also called pincer 25 ligands, impart better thermal stability to complexes when bound with the metal center than do bidentate ligands. ${ }^{3}$ Therefore, Ir complexes composed of pincer ligands are believed to exhibit excellent thermal stability, which is beneficial for fabricating OLEDs and the stability of the devices that they are included in.

30 Williams and Haga reported independently on Ir complexes composed of pincer ligands and their strong emission properties. ${ }^{4}$ Although their reports alluded to the great potential of pincer Ir complexes as emissive materials, there are only limited examples of pincer Ir complexes being applied to manufacturing OLEDs. ${ }^{5}$

35 Ir complexes that contain 2-phenylbenzothiazole have good emissive performances, and therefore, tridentate ligands that are composed of two benzothiazole units are promising pincer ligand candidates. The pincer ligand was synthesized originally as a ligand of a Pt complex in our previous study. ${ }^{6}$ We herein report 40 on the synthesis of Ir complexes composed of benzothiazolebased pincer ligands and their performance as emitting materials

${ }^{a}$ Tsukuba Research Center for Interdisciplinary Materials Science (TIMS), Graduate School of Pure and Applied Sciences, University of Tsukuba, 11-1, Tennodai, Tsukuba, Japan; E-mail: kanbara@ims.tsukuba.ac.jp

${ }^{b}$ Department of Applied Chemistry, Faculty of Science and Engineering, Chuo University, 1-13-27, Kasuga, Bunkyo-ku, Tokyo, Japan.

$\uparrow$ Electronic Supplementary Information (ESI) available: [details of any supplementary information available should be included here]. See DOI: $10.1039 / \mathrm{b} 000000 \mathrm{x} /$ in OLEDs.

1,3-Bis(2-benzothiazolyl)-4,6-dimethylbenzene (bbtxH) was synthesized from 1,3-diiodo-4,6-dimethylbenzene by the Pd${ }_{45}$ catalyzed direct arylation of benzothiazole in $69 \%$ yield. $^{7}$ To check the reactivity of the ligand, the reaction between (tpy) $\mathrm{IrCl}_{3}$ (tpy $=$ terpyridine) and bbtxH at $210{ }^{\circ} \mathrm{C}$ in ethylene glycol was examined (Scheme 1). After treatment using $\mathrm{NH}_{4} \mathrm{PF}_{6}$, dicationic $\left[\operatorname{Ir}(\mathbf{b b t x})\left(\right.\right.$ tpy $\left._{)}\right) \mathbf{2 P F}_{6}$ was obtained in $66 \%$ yield through ${ }_{50}$ purification by crystallization. Although the reaction resulted in a single product, the combination of (tpy) $\mathrm{IrCl}_{3}$ and 1,3-bis(2benzothiazolyl)-5-methylbenzene ${ }^{6}$ gave a mixture of products, presumably due to undesired cyclometallating reactions at positions such as 4 or 6 on the central benzene moiety. These 55 results indicate that two methyl groups at 4 and 6 positions on bbtxH play important roles in the selective cyclometallation at the 2 position. The reaction of bbtxH and $\mathrm{IrCl}_{3} \bullet 4 \mathrm{H}_{2} \mathrm{O}$ gave the Cl-bridging dimer complex $\left[\mathbf{I r}(\mathbf{b b t x}) \mathbf{C l}_{\mathbf{2}}\right]_{\mathbf{2}}$ in $89 \%$ yield (Scheme 1). Since $\left[\operatorname{Ir}(\mathbf{b b t x}) \mathbf{C l}_{2}\right]_{2}$ is insoluble in commonly used organic 60 solvents such as $\mathrm{CHCl}_{3}$, THF, DMF, and DMSO, the complex was characterized by mass spectrometry and elemental analysis. $\left[\boldsymbol{I r}(\mathbf{b b t x})(\mathbf{t p y}) \mathbf{2 P F}_{\mathbf{6}}\right.$ was also obtained from $\left[\boldsymbol{I r}(\mathbf{b b t x}) \mathbf{C l}_{\mathbf{2}}\right]_{\mathbf{2}}$ and terpyridine in $64 \%$ yield. The reaction of $\left[\operatorname{Ir}(\mathbf{b b t x}) \mathbf{C l}_{2}\right]_{2}$ with 2-

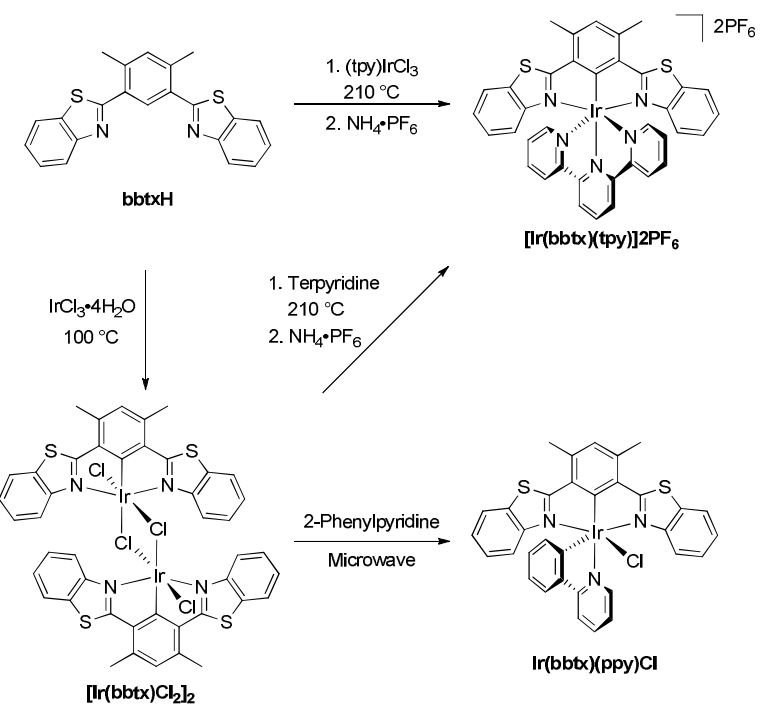

Scheme 1. Syntheses of Ir complexes with a benzothiazolebased tridentate ligand. 
phenylpyridine was carried out by applying microwave radiation for $4 \mathrm{~min}$; it resulted in a neutral complex, $\operatorname{Ir}(\mathbf{b b t x})(\mathbf{p p y}) \mathbf{C l}$, in $76 \%$ yield. Applying microwave radiation was better than employing conventional heating in terms of the yield, at $76 \%$ 5 versus $32 \%$, and a reaction time of 4 min versus $20 \mathrm{~h}$, respectively. ${ }^{8}$

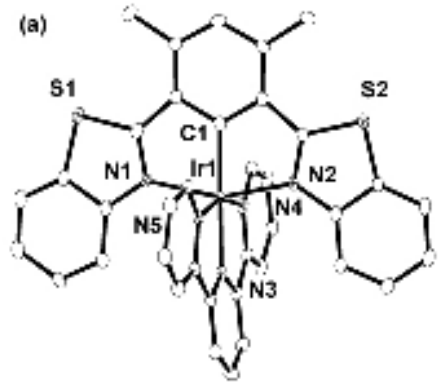

(b)

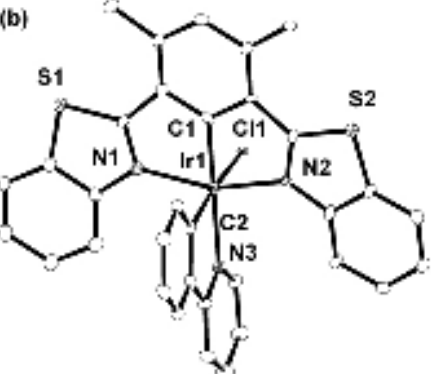

${ }_{10}$ Fig. 1. ORTEP drawings of (a) $[\operatorname{Ir}(\mathbf{b b t x})(\mathbf{t p y})] \mathbf{2} \mathbf{P F}_{\mathbf{6}}$ and (b) $\operatorname{Ir}(\mathbf{b b t x})(\mathbf{p p y}) \mathbf{C l}$ with thermal ellipsoids shown at the $30 \%$ probability level. Hydrogen atoms, counter anions, and solvating molecules are omitted for clarity.

The solid-state structures of $[\operatorname{Ir}(\mathbf{b b t x})(\mathbf{t p y})] 2 \mathbf{P F}_{\mathbf{6}}$ and $\operatorname{Ir}(\mathbf{b b t x})(\mathbf{p p y}) \mathbf{C l}$ were determined by X-ray diffraction studies (Fig. 1). ${ }^{9,10}$ Both complexes possessed octahedral geometry around the Ir center. In $\operatorname{Ir}(\mathbf{b b t x})(\mathbf{p p y}) \mathbf{C l}$, the cyclometalated carbon of ppy was located at the trans position of the $\mathrm{Cl}$ ligand, 20 which is consistent with the reported structure of the Ir pincer complex. ${ }^{4}$

25

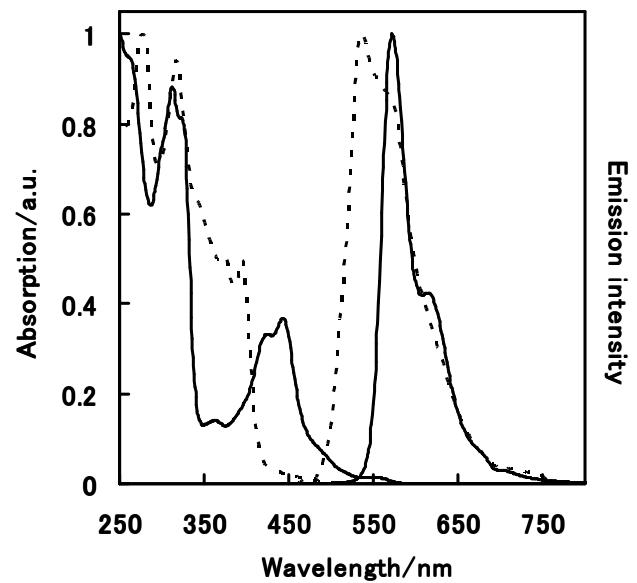

Fig. 2. UV/Vis absorption and photoluminescence spectra of $\left[\operatorname{Ir}(\mathbf{b b t x})(\mathbf{t p y}) \mathbf{2}_{\mathbf{2}} \mathbf{P F}_{\mathbf{6}}\right.$ in $\mathrm{CH}_{3} \mathrm{CN}$ at r.t. (dashed line) and ${ }_{40} \mathbf{I r}(\mathbf{b b t x})(\mathbf{p p y}) \mathbf{C l}$ in $\mathrm{CH}_{2} \mathrm{Cl}_{2}$ at r.t. (solid line).
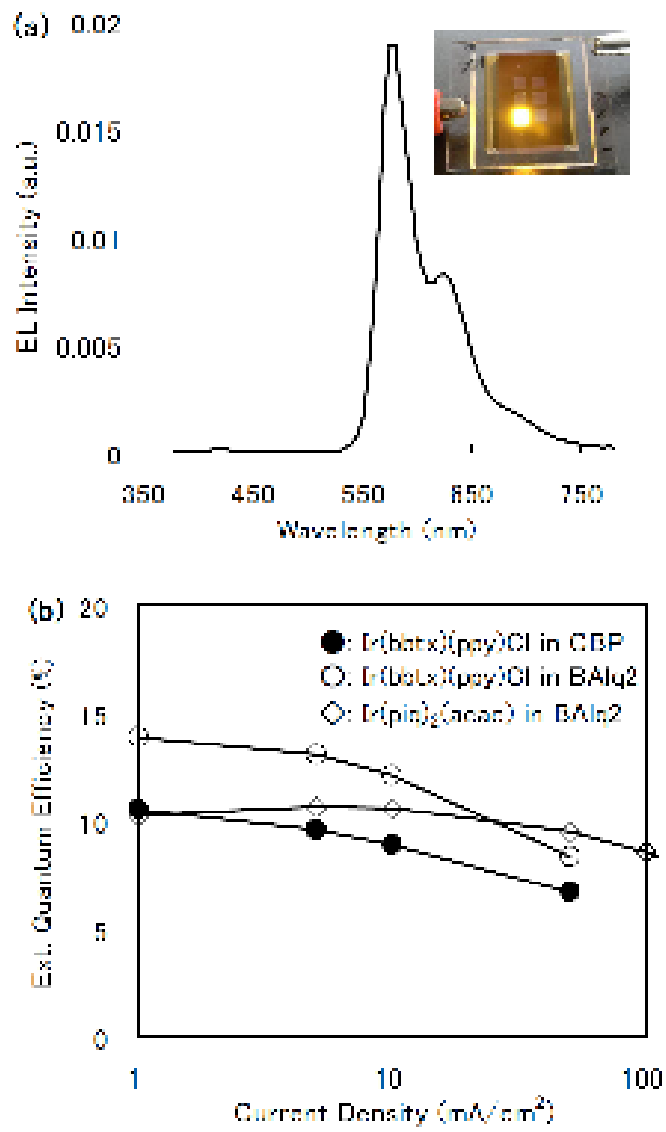

${ }_{70}$ Fig. 3. (a) Electroluminescence (EL) spectrum of device I (inset: photograph of EL of the device at $3 \mathrm{~V}$ ). (b) External quantum efficiencies of devices I, II, and III.

The UV/Vis absorption and photoluminescence spectra of ${ }_{75}\left[\operatorname{Ir}(\mathbf{b b t x})(\mathbf{t p y}) \mathbf{2 P F}_{\mathbf{6}}\right.$ and $\operatorname{Ir}(\mathbf{b b t x})(\mathbf{p p y}) \mathbf{C l}$ at r.t. are shown in Fig. 2. $\mathbf{I r}(\mathbf{b b t x})(\mathbf{p p y}) \mathbf{C l}$ exhibited characteristic absorption at around $450 \mathrm{~nm}$, and this absorption was absent for $[\mathbf{I r}(\mathbf{b b t x})(\mathbf{t p y})] \mathbf{2} \mathbf{P F}_{\mathbf{6}}$. The absorption was assigned tentatively to metal-to-ligand charge transfer (MLCT) on the basis of comparisons with Ir complexes 80 composed of NCN ligands. ${ }^{4} \mathbf{I r}(\mathbf{b b t x})(\mathbf{p p y}) \mathbf{C l}$ exhibited a strong emission at $572 \mathrm{~nm}$ when excited at $443 \mathrm{~nm}$. The emission spectrum had a vibrational structure with a small side band at $1223 \mathrm{~cm}^{-1}$. The quantum yield of $\operatorname{Ir}(\mathbf{b b t x})(\mathbf{p p y}) \mathbf{C l}$ was as high as $89 \%$ in degassed $\mathrm{CH}_{2} \mathrm{Cl}_{2}$ at r.t. The emission lifetime of ${ }_{85} \operatorname{Ir}(\mathbf{b b t x})(\mathbf{p p y}) \mathbf{C l}$ was $1.1 \times 10^{-6} \mathrm{~s}$. Since the quantum yield was comparable to $\operatorname{Ir}(\text { ppy })_{3},{ }^{11} \mathbf{I r}(\mathbf{b b t x})(\mathbf{p p y}) \mathbf{C l}$ was expected to have high potential for use as an emissive material in OLEDs. On the other hand, $[\mathbf{I r}(\mathbf{b b t x})(\mathbf{t p y})] \mathbf{2} \mathbf{P F}_{\mathbf{6}}$ exhibited a weak emission at $537 \mathrm{~nm}$, where the quantum yield was less than $0.1 \%$ even in 90 degassed $\mathrm{CH}_{3} \mathrm{CN}$. The low quantum yield of $[\operatorname{Ir}(\mathbf{b b t x})(\mathbf{t p y})] \mathbf{2} \mathbf{P F}_{\mathbf{6}}$ is presumably due to low energy level of a d orbital on the Ir center, which inhibits MLCT leading to effective emission. ${ }^{4 \mathrm{i}}$

The thermal stability of $\mathbf{I r ( b b t x ) ( p p y ) C l}$ was evaluated by 95 thermogravimetric analysis. The 5\% decomposition temperature of $\operatorname{Ir}(\mathbf{b b t x})$ (ppy)Cl was $480{ }^{\circ} \mathrm{C}$, which was higher than that of $\operatorname{Ir}(\mathrm{ppy})_{3}$ at $413{ }^{\circ} \mathrm{C} .^{2 \mathrm{c}}$ This result proved to be the advantage of the pincer ligand in terms of thermal stability. Owing to its high 
thermal stability and high fluorescence quantum yield, $\operatorname{Ir}(\mathbf{b b t x})(\mathbf{p p y}) \mathbf{C l}$ was evaluated as a candidate dopant for the emitting layer of OLEDs. To examine the electrophosphorescent properties of $\mathbf{I r}(\mathbf{b b t x})(\mathbf{p p y}) \mathbf{C l}$, three OLEDs (I, II, and III) were 5 fabricated with different host materials and dopants. In the emission layer of device I, 4,4'-bis(9-dicarbazolyl)-2,2'-biphenyl (CBP) was used as the host material and $\operatorname{Ir}(\mathbf{b b t x})(\mathbf{p p y}) \mathbf{C l}$ was used as the dopant. In device II, the host material was bis(2methyl-8-quinolinolato)phenolatealuminium(III) (BAlq2) instead 10 of CBP and the dopant was $\operatorname{Ir}(\mathbf{b b t x})(\mathbf{p p y}) \mathbf{C l}$. In device III, the host material was BAlq2 and the dopant was bis(1phenylisoquinoline)(acetylacetonate)iridium(III), $\operatorname{Ir}(\text { piq) })_{2}$ (acac). ${ }^{12}$ Fig. 3a shows the electroluminescence spectrum of device I, which is similar to its photoluminescence spectrum in the diluted 15 solution state. This result indicates that $\operatorname{Ir}(\mathbf{b b t x})(\mathbf{p p y}) \mathbf{C l}$ was well dispersed throughout CBP. The coordinates of the CIE chromaticity of device I were $\mathrm{x}=0.55$ and $\mathrm{y}=0.44$ at $1 \mathrm{~mA} / \mathrm{cm}^{2}$. The external quantum efficiency of device I was $10.5 \%$ at 1 $\mathrm{mA} / \mathrm{cm}^{2}$ (Fig. 3b). Since device II possessed a higher external 20 quantum efficiency $(14.0 \%)$ than device I, BAlq2 was a suitable host material for $\operatorname{Ir}(\mathbf{b b t x})(\mathbf{p p y}) \mathbf{C l}$. In addition, device II had the advantage of a longer lifetime of electroluminescence than device I (Fig. S-2) $\dagger$ Device II had an external quantum efficiency comparable to device III with $\operatorname{Ir}(\text { piq })_{2}($ acac $)$, which is ${ }_{25}$ representative of a red emission dopant. ${ }^{12}$

In summary, the neutral Ir complex that contains the benzothiazole-based pincer ligand has a higher quantum yield and thermal stability than Ir complexes bearing bidentate ligands. The Ir complex can serve as an efficient emissive dopant in ${ }_{30}$ OLEDs. This investigation was an important step for the development of pincer Ir complexes as emissive materials for OLEDs. Further investigations such as optimizing devices that contain $\mathbf{I r ( b b t x ) ( p p y ) C l}$ as a dopant and developing new designs of pincer ligands are currently underway.

\section{${ }_{35}$ Acknowledgements}

We are grateful to the Chemical Analysis Center of the University of Tsukuba for X-ray diffraction studies, elemental analyses, and NMR spectroscopy in this research. We thank Prof. T. Nabeshima, Prof. M. Yamamura, Prof. Y. Nishimura, Dr. T. 40 Inoue, and S. Kitagawa for assistance in measuring the quantum yields, emission lifetime, and electrophosphorescent properties of the complexes.

\section{Notes and references}

1 (a) M. A. Baldo, S. Lamansky, P. E. Burrows, M. E. Thompson and S.

45 R. Forrest, Appl. Phys. Lett., 1999, 75, 4; (b) M. Ikai, S. Tokito, Y. Sakamoto, T. Suzuki and Y. Taga, Appl. Phys. Lett., 2001, 79, 156; (c) C. Adachi, M. A. Baldo, M. E. Thompson and S. R. Forrest, J. Appl. Phys., 2001, 90, 5048; (d) M. S. Lowry and S. Bernhard, Chem. Eur. J., 2006, 12, 7970; (e) C. Ulbricht, B. Beyer, C. Friebe, A. Winter and U.

50 S. Schubert, Adv. Mater., 2009, 21, 4418; (f) Y. You and S. Y. Park, Dalton Trans., 2009, 1267; g) Y. Chi and P.-T. Chou, Chem. Soc. Rev., 2010, 39, 638.

2 (a) S. Lamansky, P. Djurovich, D. Murphy, F. Abdel-Razzaq, R. Kwong, I. Tsyba, M. Bortz, B. Mui, R. Bau and M. E. Thompson, Inorg. Chem., 5 2001, 40, 1704; (b) S. Lamansky, P. Djurovich, D. Murphy, F. AbdelRazzaq, H.-E. Lee, C. Adachi, P. E. Burrows, S. R. Forrest and M. E. Thompson, J. Am. Chem. Soc., 2001, 123, 4304; (c) A. Tsuboyama, H. Iwawaki, M. Furugori, T. Mukaide, J. Kamatani, S. Igawa, T.
Moriyama, S. Miura, T. Takiguchi, S. Okada, M. Hoshino and K. Ueno, 60 J. Am. Chem. Soc., 2003, 125, 12971; (d) J.-Y. Hung, Y. Chi, I.-H. Pai, Y.-C. Yu, G.-H. Lee, P.-T. Chou, K.-T. Wong, C.-C. Chen and C.-C Wu, Dalton Trans., 2009, 6472; (e) K. Tsuchiya, S. Yagai, A. Kitamura, T. Karatsu, K. Endo, J. Mizukami, S. Akiyama and M. Yabe, Eur. J. Inorg. Chem. 2010, 926, (f) V. K. Rai, M. Nishiura, M. Takimoto and Z. Hou, 65 Chem. Commun., 2011, 47, 5726

3 M. Albrecht and G. van Koten, Angew. Chem., Int. Ed., 2001, 40, 3750.

4 (a) A. J. Wilkinson, A. E. Goeta, C. E. Foster and J. A. G. Williams, Inorg. Chem., 2004, 43, 6513; (b) A. J. Wilkinson, H. Puschmann, J. A. K. Howard, C. E. Foster and J. A. G. Williams, Inorg. Chem., 2006, 45,

$70 \quad 8685$; (c) V. L. Whittle and J. A. G. Williams, Inorg. Chem., 2008, 47 6596; (d) T. Yutaka, S. Obara, S. Ogawa, K. Nozaki, N. Ikeda, T. Ohno, Y. Ishii, K. Sakai and M. Haga, Inorg. Chem., 2005, 44, 4737; (e) S. Obara, M. Itabashi, F. Okuda, S. Tamaki, Y. Tanabe, Y. Ishii, K. Nozaki and M. Haga, Inorg. Chem., 2006, 45, 8907; (f) L. Yang, F. Okuda, K. 75 Kobayashi, K. Nozaki, Y. Tanabe, Y. Ishii and M. Haga, Inorg. Chem., 2008, 47, 7154; (g) M. Ashizawa, L. Yang, K. Kobayashi, H. Sato, A. Yamagishi, F. Okuda, T. Harada, R. Kuroda and M. Haga, Dalton Trans., 2009, 1700; (h) J. A. G. Williams, A. J. Wilkinson and V. L. Whittle, Dalton Trans., 2008, 2081; (i) J. A. G. Williams, Chem. Soc. 80 Rev., 2009, 38, 1783.

5 D. Choi, T. Kim, S. M. Reddy and J. Kang, Inorg. Chem. Commun., 2009, 12, 41.

6 K. Okamoto, T. Kanbara, T. Yamamoto and A. Wada, Organometallics, 2006, 25, 4026

857 (a) A. Yokooji, T. Okazawa, T. Satoh, M. Miura and M. Nomura, Tetrahedron, 2003, 59, 5685; (b) D. Alagille, R. M. Baldwin and G. D. Tamagnan, Tetrahedron Lett., 2005, 46, 1349; (c) A. Mori, A. Sekiguchi, K. Masui, T. Shimada, M. Horie, K. Osakada, M. Kawamoto, T. Ikeda, J. Am. Chem. Soc., 2003, 125, 1700.

908 H. Konno and Y Sasaki, Chem. Lett., 2003, 32, 252.

9 Crystallographic details for $[\mathbf{I r}(\mathbf{b b t x})(\mathbf{t p y})] 2 \mathbf{P F}_{\mathbf{6}} \cdot 2 \mathrm{DMF}$; $\mathrm{C}_{43} \mathrm{H}_{40} \mathrm{~N}_{7} \mathrm{~F}_{12} \operatorname{IrO}_{2} \mathrm{P}_{2} \mathrm{~S}_{2}, M=1233.1$, Rigaku RAXIS-RAPID (Mo $K \alpha$ radiation), $T=88 \mathrm{~K}$, Triclinic spacegroup $P-1, a=8.8979(3) \AA, b=$ 14.1372(5) $\AA, c=19.0729(6) \AA, \alpha=97.1587$ (12), $\beta=90.6934(11), \gamma$ ${ }_{95}=110.3673(12)^{\circ}, V=2227.70(13) \AA^{3}, Z=2, D_{\text {calc }}=1.838 \mathrm{~g} / \mathrm{cm}^{3}$, 21949 measured reflections, 10019 independent reflections $\left[R_{\mathrm{int}}=\right.$ $0.079], R_{1}[\mathrm{I}>2 \sigma(I)]=0.0404, \mathrm{w} R_{2}($ all data $)=0.0969, \mathrm{GOF}=1.078$. CCDC 834013. Selected bond distances of $[\mathbf{I r}(\mathbf{b b t x})(\mathbf{t p y})] \mathbf{2} \mathbf{P F}_{\mathbf{6}}(\AA)$ : $\mathrm{Ir}-\mathrm{C} 1=1.972(4) \mathrm{Ir}-\mathrm{N} 1=2.093(3), \mathrm{Ir}-\mathrm{N} 2=2.087(4), \mathrm{Ir}-\mathrm{N} 3=2.030(3)$, $100 \quad$ Ir-N4 $=2.066(3)$, Ir-N5 $=2.056(3)$

10 Crystallographic details for $\left[\mathbf{I r}(\mathbf{b b t x})(\mathbf{p p y}) \mathbf{C l} \cdot 2 \mathrm{CHCl}_{3}\right.$; $\mathrm{C}_{35} \mathrm{H}_{25} \mathrm{~N}_{3} \mathrm{IrS}_{2} \mathrm{Cl}_{7}, \quad M=992.1$, Rigaku RAXIS-RAPID (Mo $K \alpha$ radiation), $T=88 \mathrm{~K}$, Triclinic spacegroup $P-1, a=9.7217(5) \AA, b=$ 12.3438(6) $\AA, c=16.1530(8) \AA, \alpha=79.6257$ (15), $\beta=87.9281(17), \gamma$ $105=71.2491(15)^{\circ}, V=1805.03(16) \AA^{3}, Z=2, D_{\text {calc }}=1.825 \mathrm{~g} / \mathrm{cm}^{3}, 17542$ measured reflections, 8161 independent reflections $\left[R_{\text {int }}=0.098\right], R_{1}[\mathrm{I}$ $>2 \sigma(I)]=0.0563, \mathrm{w} R_{2}$ (all data) $=0.1348, \mathrm{GOF}=0.943$. CCDC 834012. Selected bond distances $(\AA)$ : Ir-C1 $=1.956(6), \operatorname{Ir}-\mathrm{C} 2=$ 2.013(7), Ir-N1 = 2.073(6), Ir-N2 = 2.083(7), Ir-N3 = 2.158(5), Ir-Cl1 = $10 \quad 2.5034(15)$

11(a) S. Sprouse, K. A. King, P. J. Spellane and R. J. Watts, J. Am. Chem. Soc., 1984, 106, 6647; (b) A. Endo, K. Suzuki, T. Yoshihara, S. Tobita, M. Yahiro and C. Adachi, Chem. Phys. Lett., 2008, 460, 155.

12 Y.-J. Su, H.-L Huang, C.-L. Li, C.-H. Chien, Y.-T. Tao, P.-T. Chou, S. 115 Datta and R.-S. Liu, Adv. Mater., 2003, 15, 884. 